\title{
Anesthesiologists' involvement in undergraduate medical education is beneficial to students and the specialty
}

\author{
Tasnim Zaman, MSc (1) · Vivesh Patel, BSc (Hons) - Daniel Cordovani, MD, MSc
}

Received: 4 November 2020/Revised: 20 December 2020/Accepted: 22 December 2020/Published online: 15 January 2021

(C) Canadian Anesthesiologists' Society 2021

\section{To the Editor,}

Anesthesiologists should be more involved in undergraduate medical education (UGME) - they currently contribute a median of 2.2 teaching hours per faculty member in the pre-clerkship curriculum at Canadian medical schools. ${ }^{1}$ Though this is a low number considering the broad spectrum of knowledge that anesthesiologists possess, it is nevertheless an $817 \%$ increase from 2001 where the median was only $14.4 \mathrm{~min}{ }^{1}$

Anesthesiologists' knowledge of physiology and pharmacology, coupled with expertise in airway, fluid, and pain management uniquely position them to teach within the UGME curriculum. Regrettably, anesthesiologists face barriers to involvement in UGME, the most glaring one being their relative inflexible schedule due to operating room commitments. ${ }^{2}$ Nevertheless, we hope to plead a convincing case as to why anesthesiologists are fundamental to early training, in hopes to foster conversations among administrators around how to better include anesthesiologists in UGME.

One example of the role that anesthesiologist can play in UGME is highlighted by the Anaesthetists' Non-Technical Skills (ANTS) checklist—a tool created by and for

T. Zaman, MSc ( $\square)$

Michael G. DeGroote School of Medicine, McMaster University, Hamilton, ON, Canada

e-mail: tasnim.zaman@medportal.ca

V. Patel, BSc (Hons)

Queen's School of Medicine, Queen's University, Kingston, ON, Canada

D. Cordovani, MD, MSc

Department of Anesthesia, Michael G. DeGroote School of

Medicine, McMaster University, Hamilton, ON, Canada anesthesiologists-for the assessment of "non-technical skills" in medical students. ${ }^{3}$ This assessment tool showed that medical students would benefit from further training in situational awareness and decision-making, both of which could aid in optimizing patient safety, whilst decreasing perioperative errors and subsequent medicolegal litigation. ${ }^{3}$ Expertise in these areas is an example of a perfectly tailored opportunity for anesthesiologists to share insight and address a need in UGME. $^{4}$

Failure to involve anesthesiologists more in UGME is a disservice to medical students and the field of anesthesiology. Medical students can benefit from learning skills identified not only on the ANTS checklist but also by the objectives in the Medical Council of Canada (MCC) Blueprint, which drives the undergraduate curricula. As physicians who are highly skilled at communication, management, and professional behaviours, the MCC Blueprint showcases important areas in which anesthesiologists are well equipped to teach. $^{3}$ The aforementioned skills can serve students well in complex clinical settings in any field. Furthermore, it is imperative for anesthesiologists to seize the opportunity of educating, influencing, and courting learners to inspire the future generation of innovators, educators, and leaders in anesthesia. Medical students deserve to learn about anesthesiology early in their training and they further deserve the potential opportunity to join the field and become invaluable assets to the specialty.

Anesthesia is a captivating area of medicine, and one that many students wish they had earlier exposure to in order to aid with their career exploration. ${ }^{5}$ At the University of Toronto, lack of exposure and knowledge of the speciality is reported as why $>70 \%$ of students did not consider anesthesia as a top career choice. ${ }^{5}$ Following 
exposure to anesthesia in upper years, $50 \%$ of students reported that they would have considered anesthesia in their top three career choices if they had been exposed to it earlier. ${ }^{5}$ The benefits of early exposure to anesthesia in UGME is not only limited to the realm of career selection. Increasing UGME involvement could garner additional respect and an appreciation by others for what they doi.e., regardless of whether students ultimately choose to pursue anesthesia, future colleagues of anesthesiologists would have a better understanding of what they do and more respect for anesthesia as a discipline. Recruitment to the specialty is not the only goal. Increased understanding of anesthesiologists' roles can also improve team dynamics and collaboration between colleagues, ultimately leading to enhanced patient care.

It appears that most, if not all, stakeholders (medical students, anesthesiologists, the MCC, and the discipline itself) can benefit from increased involvement of anesthesiologists in UGME. A student's life could take a positive turn should they have the pleasure of learning essential skills from accomplished anesthesiologists. Students and anesthesiologists are missing out on fostering mentors and mentees, respectively—a very rewarding and necessary component of medical training. ${ }^{2}$ Furthermore, early involvement of anesthesiologists in UGME curriculum across Canada may increase the likelihood that more talented students do not miss out on the possibility to be inspired to join the ranks among anesthesiologists in pursuing a fascinating career.
Disclosures None.

Funding statement None.

Editorial responsibility This submission was handled by Dr. Hilary P. Grocott, Former Editor-in-Chief, Canadian Journal of Anesthesia.

\section{References}

1. Hamlin $C$, Bhangu $K$, Villafranca A, et al. Participation of Canadian anesthesiology departments in undergraduate medical education. Can J Anesth 2017; 64: 16-28.

2. Naik VN. Pre-clerkship teaching: are we missing an opportunity? Can J Anesth 2017; 64: 6-9.

3. Lee A, Finstad A, Gawad N, Boet S, Raiche I, Balaa F. Nontechnical skills (NTS) in the undergraduate surgical and anesthesiology curricula: are we adequately preparing medical students? J Surg Educ 2020. DOI: https://doi.org/10.1016/j.jsurg. 2020.08.001.

4. Smith A, Carey C, Sadler J, Smith H, Stephens R, Frith $C$. Undergraduate education in anaesthesia, intensive care, pain, and perioperative medicine: the development of a national curriculum framework. Med Teach 2019; 41: 340-6.

5. Adudu OP, Le NH, Devito I, Campbell FA, Levine MF. Medical student impressions of anesthesiology and anesthesiologists. Can J Anesth 2010; 57: 792-3.

Publisher's Note Springer Nature remains neutral with regard to jurisdictional claims in published maps and institutional affiliations. 